\title{
Origens \\ da quiralidade molecular
}

Roger A. Hegstrom a)

A origem da pureza quiral dos compostos químicos que se encontram nos organismos vivos é um dos problemas mais fundamentais para o qual as ciências da biologia molecular e da evolução química não têm ainda uma solução. Este artigo destina-se a apresentar uma breve introdução a este problema a um nivel elementar. É possível encontrar na literatura artigos de revisão mais completos ${ }^{1}$.

A palavra "quiral" vem do grego da palavra "cheir" que significa mão. Por definição, qualquer objecto é quiral se não for possivel sobrepô-lo à sua imagem num espelho plano no espaço tridimensional normal. Exemplos correntes de objectos quirais são as mãos humanas, os saca-rolhas e as escadas em caracol.

Como é bem conhecido da química, muitas moléculas são quirais. Um dos exemplos mais simples é uma molécula como o CHFC1Br que contém um único átomo central de carbono com quatro átomos ou grupos de átomos diferentes a ele ligados. Por causa da orientação tetraédrica das quatro ligações em torno do átomo de carbono central, uma molécula como esta é diferente da sua imagem num espelho (ao contrário do que sucede, por exemplo, com uma molécula de água, que é idêntica à sua imagem num espelho plano e é portanto aquiral). Uma molécula quiral (também chamada assimétrica) e a sua imagem num espelho plano são chamadas enantiómeros ou isómeros ópticos. De acordo com uma convenção algo arbitrária, que não é importante para os objectivos deste artigo, uma é chamada o isómero R (do latim "rectus") e a outra, o isómero S (do latim “sinister"). Um composto quiralmente puro é constituido por moléculas idênticas do isómero $\mathbf{R}$ (ou do S). Uma mistura equimolar dos isómeros $\mathrm{R}$ e $\mathrm{S}$ é chamada uma mistura racémica. $\mathrm{O}$ isomerismo óptico foi descoberto há mais de cem anos por Louis Pasteur.

Os isómeros ópticos têm propriedades físicas e químicas - tais como ponto de fusão, estabilidades, energias de ionização, etc. - idênticas.* Eles só podem ser distinguidos um do outro por meio de uma sonda que explore a sua quiralidade como seja a luz polarizada. Um composto quiral faz rodar o plano da luz polarizada linearmente; o seu enantiómetro faz rodar o plano de um ângulo igual, mas na direcção oposta. Devido a esta propriedade singular os compostos quirais denominam-se "opticamente activos". As misturas racémicas e os compostos aquirais são opticamente inactivos. Uma outra sonda que distingue entre enantiómeros é qualquer substância quiralmente pura, uma vez que ela interactua de uma maneira diferente com enantiómeros R e S, no mesmo sentido em que para uma mão humana direita não serve igualmente uma luva para a mão direita e uma luva para a mão esquerda.
Quando se sintetizam compostos quirais no laboratório em condições normais o resultado inevitável é a obtenção de uma mistura racémica ${ }^{* *}$, a não ser que se tomem precauções especiais para introduzir uma influência assimétrica (por exemplo, um catalisador quiral). Este resultado é de esperar por razões de simetria, uma vez que na ausência de uma influência assimétrica as moléculas dos produtos $\mathrm{R}$ e $\mathrm{S}$ são igualmente prováveis. Um exemplo disto é a famosa experiência de Miller-Urey ${ }^{2}$ em que os aminoácidos produzidos por uma descarga eléctrica em reagentes gasosos (água, metano, azoto e amoníaco) foram identificados como sendo misturas racémicas.

\section{MOLÉCULAS QUIRAIS NOS ORGANISMOS VIVOS}

Pasteur foi o primeiro a fazer notar a relação especial existente entre a quiralidade molecular e os organismos vivos. Ele notou que a maior parte dos produtos orgânicos naturais são quiralmente puros, enquanto que os produtos artificiais obtidos no laboratório e as espécies minerais são, ou aquirais, ou, se são quirais, ocorrem igualmente em ambas as formas enantioméricas. Desde a época de Pasteur tem-se chegado à conclusão que são quiralmente puros não só os produtos naturais dos organismos, mas também as suas moléculas constituintes mais fundamentais, nomeadamente as proteinas enzimáticas e os ácidos nucleicos. Além disso, as proteinas são constituídas apenas pelos isómeros $\mathrm{S}$ dos aminoácidos e os ácidos nucleicos contêm apenas os isómeros $\mathrm{R}$ dos açúcares (ribose). Uma consequência desta quiralidade é que os organismos vivos são capazes de distinguir entre enantiómetros e muitas vezes reagem de uma maneira muito diferente com os isómeros $\mathrm{R}$ e S de um dado composto quiral. Por exemplo, o S-glutamato monossódico usa-se correntemente como um estimulante do sabor para as papilas gustativas, que não são estimuladas pelo isómero $\mathrm{R}$. Um exemplo ainda mais flagrante é o da S-fenilalanina, que é inócua para os seres humanos, enquanto que o isómero $\mathrm{R}$, quando ingerido, leva à loucura 3 ! Os microorganismos são também capazes de distinguir entre "forma direita" e "forma esquerda", como foi por exemplo

a) Department of Chemistry, Wake Forest University, Winston-Salem, North Carolina 27109, USA.

* Por causa da interacção fraca violadora da paridade esta afirmação só é verdadeira numa muito boa primeira aproximação conforme é discutido a seguir no artigo.

** Dentro dos limites definidos pela precisão experimental; se o número de moléculas do produto for pequeno, esta afirmação tem que ser modificada conforme se discute a seguir no artigo. 
demonstrado pela experiência de Pasteur, em que um bolor produtor de penicilina destruiu selectivamente ácido R-tartárico deixando o isómero $\mathrm{S}$ intacto.

\section{O PROBLEMA DA ORIGEM}

Porque é que os organismos vivos fazem um uso tão grande de substâncias quiralmente puras? A quiralidade dos produtos naturais pode ser entendida como sendo uma consequência geral da quiralidade das proteinas, dado que estas catalisam a produção dos referidos produtos. Porque é que as proteínas são, então, quiralmente puras? Estudos experimentais e teóricos mostram que um certo número de estruturas poliméricas incluindo proteinas e ácidos nucleicos, quando constituídas por monómeros de quiralidade uniforme, se formam mais rapidamente e são mais estáveis do que quando são formadas a partir de uma mistura racémica. Por esta e por outras razões parece natural que tenham sido usados aminoácidos e açúcares quiralmente puros para a construção dos respectivos polímeros!

As questões principais consideradas neste artigo são (1) como é que se originou esta pureza quiral, uma vez que são as misturas racémicas, e não os compostos quiralmente puros, os produtos da síntese abiótica normal e (2) porque é que só se encontram aminoácidos $\mathrm{S}$ e açúcares $\mathbf{R}$ nas proteínas e nos ácidos nucleicos, as moléculas mais fundamentais de todas as que constituem os organismos, em vez de se encontrarem os seus enantiómeros.

Podia parecer à primeira vista que a natureza tinha que seleccionar entre forma esquerda e forma direita duas vezes, uma vez no caso dos aminoácidos e outra vez no caso dos açúcares. Isto não foi, no entanto, necessário, porque a interacção entre aminoácidos $\mathrm{S}$ e açúcares $\mathrm{R}$ é, do ponto de vista energético, diferente das correspondentes interacções S-S ou R-R. Daqui resulta que, se os açúcares $\mathrm{R}$ foram, por exemplo, seleccionados em primeiro lugar, então podia muito bem ter-se seguido a selecção de aminoácidos $\mathrm{S}$ em lugar de aminoácidos $\mathbf{R}$ por razões energéticas. Daqui para diante os aminoácidos $\mathrm{S}$ e os açúcares $\mathrm{R}$ serão chamados, de uma maneira arbitrária, da forma esquerda e, no mesmo sentido, a vida terrestre será referida como sendo esquerda.

O problema da origem da pureza quiral está intimamente associado ao problema da origem da vida. E geralmente aceite que a vida, tal como a conhecemos, não podia existir sem pureza quiral. De facto, a actividade óptica foi até proposta como um critério para reconhecer a vida extraterrestre. Daqui resulta que, se fosse possível responder à pergunta sobre como é que a pureza quiral se originou, uma pergunta que é conceptualmente mais simples do que a questão da origem da vida, a resposta à pergunta mais simples poderia muito bem dar indicações sobre a mais difícil.

Em que medida é que estas questões sobre origens podem ser respondidas através da investigação científica? Esta é, certamente, uma questão muito controversa. Segundo um determinado ponto de vista, estas perguntas nunca poderão ter resposta porque elas referem-se a um dado conjunto de acontecimentos que ocorreram no passado e o carácter que a teoria tem para apresentar explicações posteriores é aparentemente inútil por causa da complexidade destes acontecimentos. No entanto, na medida em que os fenómenos em causa se regem pela lei natural, eles podem, em princípio, ser repetidos no laboratório. Criar um organismo vivo no laboratório a partir de moléculas simples seria tão es- clarecedor e importante como responder à pergunta sobre como é que a vida actual se originou no tempo. É neste sentido que a ciência experimental, guiada pela teoria, poderá ser capaz de responder a estas questões fundamentais.

\section{ALGUMAS SOLUÇÕES APONTADAS}

Até agora, ainda não foi encontrada uma resposta definitiva à questão da origem da pureza quiral. Antes de considerarmos algumas possibilidades, reformulemos a questão principal. Como é que se originou a pureza quiral das moléculas biológicas e como é que só os aminoácidos $\mathrm{S}$ e só os açúcares (ribose) $\mathrm{R}$ é que se encontram, respectivamente, nas proteinas enzimáticas e nos ácidos nucleicos, quando aparentemente a combinação dos seus enantiómeros teria servido igualmente bem? (Presume-se que a imagem num espelho plano da vida tal como a conhecemos funcionaria igualmente bem).

Desde o tempo de Pasteur que tem sido apresentado um certo número de respostas diferentes! Uma sugestão é que a pureza quiral teve uma origem biótica. Se a pureza quiral não fosse essencial para a vida no início, esta poderia ter usado ambos os isómeros ópti$\cos$ e a pureza quiral poderia ter surgido por selecção natural. O "sinal" da quiralidade, isto é, enantiómeros esquerdos em vez de enantiómeros direitos, teria sido simplesmente um resultado do acaso. Em alternativa, se a pureza quiral tivesse sido essencial para a vida, alguns dos organismos primitivos podiam ter sido molecularmente puramente esquerdos e outros puramente direitos. Depois, no decurso da evolução biológica, um organismo poderia ter obtido uma certa vantagem devido a uma mutação, não relacionada com o sentido direito ou esquerdo, o que teria como resultado a sua sobrevivência e a extinção dos outros organismos. Mais uma vez o sinal da quiralidade sobrevivente seria devida ao acaso.

Também foi sugerido que a pureza quiral teria tido uma origem abiótica. Em tempos prebióticos ter-se-ia gerado um excesso de isómeros esquerdos. Este excesso teria então sido amplificado até à obtenção da pureza quiral, quer durante o período de evolução química que deve ter precedido a origem da vida, de tal modo que substâncias quiralmente puras estariam prontas a ser incorporadas nos primeiros organismos vivos, quer durante a evolução biológica.

Um certo número de mecanismos possíveis para a geração de um excesso quiral foi sugerido no contexto da hipótese da origem abiótica. Um tipo de mecanismos, ao qual se pode chamar um mecanismo estatístico, foi a geração de um excesso quiral a partir de flutuações estatísticas. É bem sabido que se se lançarem ao ar 100 moedas, a probabilidade de que saiam exactamente 50 caras e 50 coroas é muito pequena, mesmo sendo as caras ou coroas igualmente prováveis para cada lançamento. Exactamente pela mesma razão, quando se produz um composto quiral em condições de simetria, é altamente improvável que o número de moléculas isoméricas $\mathrm{R}$ seja igual ao número de moléculas isoméricas $\mathrm{S}$. É de facto muito mais provável que haja um excesso, seja de R, seja de S (com igual probabilidade). Quanto menor for o número de moléculas de produto, mais provável será um excesso relativo maior. Pode-se imaginar o caso extremo de se formar apenas uma molécula quiral; neste caso o produto seria quiralmente puro, uma vez que a molécula tem que ser $\mathbf{R}$, 
ou S. Evidentemente que o sinal da quiralidade resultante de um mecanismo estatístico seria devido ao acaso.

Outros mecanismos sugeridos para a geração de um excesso quiral no contexto da hipótese da origem abiótica baseiam-se na ideia de que uma vizinhança ou força assimétrica local poderá favorecer um enantiómetro em relação ao outro. Um mecanismo deste tipo pode ser denominado um mecanismo de causa local ${ }^{4}$. Um exemplo específico é a acção da luz polarizada circularmente, que existe sob duas formas, direita e esquerda. Por exemplo, se numa determinada região uma dessas duas formas se encontra presente em excesso na luz solar, então a luz solar será absorvida em quantidades diferentes por um enatiómero $\mathrm{R}$ e por um $\mathrm{S}$, pelo que por meio de processos fotoquímicos é possível produzir um excesso de um enantiómetro a partir de uma mistura racémica. Outro exemplo deste tipo de mecanismo é a adsorção selectiva de um enantiómero à superfície de uma substância quiral como seja um cristal de quartzo. Uma vez que se encontram na natureza cristais de quartzo direitos e esquerdos, de uma abundância local de uma das duas formas podia ter resultado um excesso de moléculas esquerdas adsorvidas que, mais tarde, teriam sido incorporadas em organismos vivos. Foram também já propostos outros mecanismos de causa local' ${ }^{1}$.

\section{VIOLAÇÃO DA PARIDADE}

No âmbito da hipótese de uma origem abiótica, tanto os mecanismos estatísticos como os mecanismos de causa local dão explicações possíveis para a origem de uma quiralidade molecular em que uma das formas esteja em excesso em relação à outra. No entanto, quer imediatamente, quer em última análise, eles atribuem o sinal da quiralidade ao acaso. No caso dos mecanismos estatísticos o papel do acaso é óbvio e no caso dos mecanismos de causa local o predomínio da forma esquerda sobre a direita pode ser sempre atribuido a condições iniciais aleatórias. Para a hipótese de uma origem biótica para a pureza óptica o sinal da quiralidade é da mesma maneira devido ao acaso. Se a vida tivese começado independentemente em muitos locais ou em muitas épocas diferentes nos primórdios da Terra e se fossem igualmente prováveis organismos esquerdos e direitos, então seria de esperar hoje na Terra a existência de ambos os tipos de vida com abundâncias aproximadamente iguais. Uma vez que só se encontra um tipo de vida (esquerdo) então ou (1) a vida começou de uma vez só ou por algumas vezes num ou em alguns locais, ou (2) a vida actual é descendente de uma ou algumas espécies evoluídas sobreviventes, ou (3) os dois tipos de vida (esquerdo e direito) são incompatíveis, ou (4) os dois tipos de vida (esquerdo e direito) não são, por qualquer razão, igualmente prováveis ab initio. Cada uma destas probabilidades ou combinaçōes delas podiam ser longamente discutidas. No entanto, como a ideia expressa em (4) é especialmente intrigante e o leitor pode não estar familiarizado com ela, o resto deste artigo será dedicado à explicação de como é que se pode dar a possibilidade (4).

A importância da violação da paridade é que ela produz uma diferença ab initio entre a forma direita e a esquerda que se baseia na lei natural. Na realidade, ela é, no momento presente, a única explicação estritamente causal possivel para o sinal da quiralidade biomolecular. Para se perceber isto é necessário considerar as simetrias das quatro forças fundamentais da nature- za. Três delas, nomeadamente a gravidade, o electromagnetismo e a força nuclear forte, conservam a paridade, o que para fins práticos não significa mais do que o seguinte. Suponhamos que ocorre um determinado processo que se rege por uma destas forças. Imaginemos agora que esse mesmo processo é observado depois de se ter reflectido num espelho plano. Se o processo reflectido no espelho é um processo que é também possivel no mundo real (em oposição a ser possível apenas no "mundo do espelho"), então a força conserva a paridade. Caso contrário, a paridade não é conservada e diz-se ter sido violada. Na natureza, a única força fundamental que viola a paridade é a interacção fraca, que causa, por exemplo, o declinio nuclear beta. Um critério específico da violação da paridade é que os electrões emitidos a partir do núcleo por declínio beta são predominantemente esquerdos: se a direcção "para cima" para um determinado electrão se está a mover, então o eixo do spin do electrão está dirigido "para baixo". Se se observar o processo de declínio beta depois de reflectido num espelho plano, "vê-se" a emissão de electrões predominantemente direitos (eixo do spin "para cima"). Como este último processo não ocorre no mundo real, a força responsável pelo declínio beta viola a paridade.

Praticamente todos os processos atómicos e moleculares são dominados pela interacção electromagnética (fundamentalmente Lei de Coulomb), que conserva a paridade. No entanto, a interacção fraca também pode participar em processos atómicos e moleculares (serão dados a seguir exemplos) e daí que a violação da paridade possa, em principio, fornecer um enantiómetro à custa do outro. Uma vez que a interacção fraca é universal, isto é, uma vez que actua da mesma maneira sempre e em toda a parte, este mecanismo para a origem da quiralidade é denominado um mecanismo de causa universal ${ }^{4}$. Ele explicaria tanto a origem da quiralidade como o sinal da quiralidade. Ele seria uma concretização da ideia de Pasteur de que a quiralidade biomolecular se tinha originado a partir de uma assimetria fundamental no Universo. Ele significaria que a Natureza tinha escolhido entre direita e esquerda apenas uma vez ao nível de forças fundamentais e que desta escolha tenha resultado a quiralidade da vida a nivel molecular. Diz-se que, ao ouvir a notícia de que a paridade era violada Wolfang Pauli exclamou, "Deus é canhoto!"'

Pouco depois da descoberta da violação da paridade ${ }^{5}$ em 1957, Vester e Ulbricht ${ }^{6}$ propuseram um mecanismo específico para a origem da quiralidade. Os electrões beta emitidos por núclçeos radioactivos na Terra prebiótica poderiam, devido à sua forma esquer$\mathrm{da}$, ter excitado ou ionizado isómeros $\mathrm{R}$ a uma velocidade diferente dos isómeros $\mathrm{S}$. Ao longo dos períodos de tempo imensuráveis da evolução química esta tendência constante poderia ter produzido um excesso de moléculas esquerdas que teriam sido favorecidas quando se originou a vida. Realizaram-se muitas experiências na tentativa de observar os efeitos desta proposta diferença de velocidades, mas os resultados obtidos foram ambíguos. Cálculos teóricos recentes ${ }^{7.8}$ sugerem que a diferença relativa na velocidade de ionização ou excitação de um par de enantiómeros por electrões beta é demasiado pequena para poder ser medida directamente, mas talvez possa ser detectável experimentalmente por métodos indirectos ${ }^{4.7}$.

Um mecanismo algo diferente envolvendo violação da paridade foi sugerido por Yamagata e Rein ${ }^{9}$, que mostraram teoricamente que a interacção fraca cria 
uma pequena diferença de energia entre uma molécula quiral e o seu enantiómero o que, em reacções químicas, poderia favorecer cineticamente um dos enantiómeros.

Não há hoje grandes dúvidas de que a interacção fraca, violadora da paridade, virá favorecer em certa medida um isómero óptico em relação ao outro. As principais questões ainda sem resposta são (1) se o sinal deste efeito favorece realmente moléculas biológicas “esquerdas", (2) se a intensidade do efeito é suficientemente grande para competir com as flutuações estatísticas e (3) se existe um mecanismo para amplificar um pequeno excesso quiral, como o que resultaria da interacção fraca, até à pureza quiral. Espera-se que, no futuro, a realização do trabalho experimental e teórico permita a obtenção de uma resposta a estas perguntas.

É também muito possível que a descoberta de vida extraterrestre possa um dia vir a favorecer uma resposta. Se os organismos extraterrestres se basearem em proteínas e ácidos nucleicos, é de esperar que estes compostos sejam quiralmente puros. Se eles forem direitos, que é o contrário do que sucede com os organismos terrestres, então as interacções fracas violadoras da paridade poderão provavelmente ser excluídas como a causa da quiralidade molecular. Se eles forem esquerdos, não se poderá tirar nenhuma conclusão até que se encontrem muitas formas de vida exclusivamente esquerdas com origens independentes (ou, talvez em certos casos, até que elas nos encontrem!). Nessa altura seria de admitir como muito provável que a vida esquerda estivesse ligada casualmente à quiralidade universal da interacção fraca.

\section{RESUMO}

Os organismos vivos têm uma característica única que é a pureza quiral uniforme das suas moléculas constituintes mais fundamentais. Embora tenha sido proposto um certo número de explicações para a origem desta pureza quiral, não foi ainda encontrada uma resposta definitiva. A interacção fraca violadora da paridade tem um interesse particular uma vez que fornece a única explicação estritamente causal possível para o sinal da quiralidade no âmbito da lei natural que hoje conhecemos. A consideração da origem e evolução da quiralidade continuará a ser uma parte importante do estudo da evolução química.

\section{REFERÊNCIAS BIBLIOGRÁFICAS}

1. W.A. Bonner, in Exobiology, C. Ponnamperuma, ed., (North-Holland, Amsterdam, 1972), pp. 170-234; B. Norden, J. Mol. Evol. 11, 313-332 (1978); V.A. Kizel, Sov. Phys. Usp. 23, $277-295$ (1980); L. Keszthely, Origins of Life 11, 9-21 (1981); T.L.V. Ulbricht, ibidi 55-70 (1981).

2. S.L. Miller e L.E. Orgel, Origins of Life on the Earth (Prentice-Hall, New Jersey, 1974).

3. L.W. Fine, Chemistry Decoded (Oxford Univ. Press, New York, 1976), p. 410.

4. D.W. Gidley, A. Rich, J. Van House, and P.W. Zitzewitz, Nature 297, 639-643 (1982).

5. Ver por exemplo M. Gardner, The Ambidextrous Universe (Scribner's Sons, New York, 1979).

6. F. Vester, T.L.V. Ulbricht, e H. Krauss, Naturwissenschaften 46, 68-69 (1959).

7. R.A. Hegstrom, Nature 297, 643-647 (1982).

8. Ya. B. Zel'dovich e D.B. Saakyan, Soviet Phys. JETP 51, 1118-1120 (1980).

9. Y. Yamagata, J. Theor. Biol. 11, 495-498 (1966); D.W. Rein, J. Molec. Evol. 4, 15-22 (1974).

\section{IMIMPE SARL}

- Analisadores de gases no ambiente e em emissão

TECO

- Amostradores de poeiras no ambiente

ANDERSEN

- Equipamento de Amostragem de gases e poeiras em emissão

ANDERSEN

- Analisadores de oxigénio, opacidade e CO em emissão

DYNATRON

- Amostradores automáticos de efluentes líquidos

ISCO

- Equipamento de análise térmica

DU PONT

- Analisadores TC/TOC/TOD 